\title{
Tempo e memória em \\ Perto do Coração Selvagem, \\ de Clarice Lispector
}

pg 24-30

Diego Luiz Müller Fascina ${ }^{1}$

Éderson Luís Silveira ${ }^{2}$

\section{Resumo}

No século XX, as formas de constituição de narrativas sofreram significativas modificações, sobretudo no que diz respeito a configurações específicas do tempo cronológico utilizado que, contrapondo-se à linearidade do romance do século XIX, foi retrabalhado, dando lugar à fusão do passado, presente e futuro, técnica conhecida como fluxo de consciência ${ }^{33}$, situada no âmbito da memória dos personagens, dentre outros recursos de subjetivação intimamente ligados ao tempo psicológico. O presente artigo visa propor uma discussão, através da análise do romance Perto do Coração Selvagem, de Clarice Lispector, a respeito da temporalidade visando comprovar como a preocupação existencial e mística dos personagens é apresentada na oscilação entre os momentos atemporais e o tempo cronológico ao qual elas estão inevitavelmente presas.

Palavras-chave: Clarice Lispector, Narrativa, Memória, Tempo.

\section{TEMPORALITY AND MEMORY IN PERTO DO CORAÇÃO SELVAGEM BY CLARICE LISPECTOR}

\begin{abstract}
In the 20th century, the forms of Constitution of narratives suffered significant changes, particularly with regard to chronological time-specific settings used which, opposed to the linearity of the 19th century novel was reworked, giving way to the fusion of the past, present and future, technique known as stream of consciousness, located under the memory of the characters, among other features of subjectivation closely linked to psychological time. This paper aims to discuss time and the specific resources used by Clarice Lispector in her first novel, Perto do Coração Selvagem, about temporality in order to demonstrate how the existential concern and mystique of the characters in the timeless moments and oscillation between the chronological time to which they are inevitably trapped. Keywords: Clarice Lispector, Narrative, Memory, Time.

\footnotetext{
1 Mestre em Letras, pela Universidade Estadual de Maringá, doutorando em Letras, pela mesma universidade. E-mail: ediliteratus@gmail.com

2 Mestrado em Estudos Linguísticos e doutorando em Letras, pela mesma universidade. E-mail: ediliteratus@gmail.com

3 Para Humphrey (1976, p. 123), “[...] o assunto principal é a consciência de um ou mais personagens; isto é, a consciência retratada serve como uma tela sobre a qual se projeta o material desses romances".
} 


\section{Pressupostos teóricos}

Trilhar os caminhos da crítica literária é uma tarefa árdua. Seja porque as lentes a ser utilizadas não são únicas ou porque as formas de (re) leituras do mundo não são estanques. Essa movência e heterogeneidade do fazer literário desloca a crítica e assinala-a como o farol de Alexandria a iluminar o oceano através das ondas de possibilidades que da obra literária podem emergir. Pensar a narrativa e as formas como esta pode se manifestar através dos séculos é pensar no papel da leitura e também na função do tempo que não pode ser pensada, a partir do século XX, de forma linear. Se a narrativa nem sempre segue um percurso de início, meio e fim através de uma sucessão linear entre passado, presente e futuro, a crítica, então, pode se debruçar sobre essa caracterísctica tecendo visadas acerca do fluxo da narrativa e os efeitos disso nas formas de narrar.

Consoante a isso, temos as contribuições de Nunes (2002) para quem é pela leitura que se concretiza a função do tempo na narrativa e que é equivocado pensar que o ato de ler é apenas um percurso linear, sem interferências, pois a cada frase se opera uma síntese memorial e, a cada nova frase, uma reserva de experiência conteudística e estilística vai se acumulando. Além deste acúmulo de experiências, a síntese memorial também abrange os atos de preenchimento dos indicadores ou registros que orientam a leitura e que se destinam a concretizá-la. Assinalar modos de narrar com temporalidades que não são lineares, portanto, implica pensar em formas de rememoração, visto que a memória dos personagens, por exemplo, se vai tecendo entre fios descontínuos o que implica em percepções de leitura diferentes daquelas produzidas por narrativas de viés linear.

Dessa forma, na primeira seção, abordarse-á a questão do tempo na narrativa moderna. $\mathrm{Na}$ segunda seção, ter-se-á o desdobramento analítico da temporalidade em Perto do coração selvagem, de Clarice Lispector e na terceira seção sobre a questão memorialística no romance. Finalmente, as considerações finais não visam o esgotamento do assunto, mas trazer um (efeito de) fechamento das ideias aqui apresentadas.

\section{O tempo na narrativa moderna}

Donaldo Schuler (1989) afirma que o romance nasceu como testemunha do declínio de um período, a Idade Média e que, em vez da imobilidade, o romance toma, ao nascer, consciência da transformação. Com a ascensão da burguesia e com a transição do medievo para a Idade Moderna, há ainda, nessa mesma época "O início da cronometria do trabalho e da produção, que levou o controle dos relógios mecânicos, depois que se tornaram mais precisos, a estenderse sobre toda a vida social" (NUNES, 2002, p.50).

Até então, nos romances do século XIX predominava-se o tempo cronológico homogêneo (metáfora dos relógios que contam instantes um após o outro). Porém, ao longo desse mesmo século, o "herói problemático" (termo cunhado por Lukács) característico do gênero romanesco vai desenvolvendo sua conturbada relação com o mundo: sente-se insatisfeito com sua subjetividade, abrindo as "portas" da narrativa ao tempo vivido, à duração interior, num processo que desemboca em alterações significativas no narrar.

\section{O tempo passou a ser visto como} uma dimensão humana, internalizado e existencializado, criando um paradoxo em relação ao tempo logicamente construído e válido para os fins da ação. Neste contexto que Olga de Sá (1979, p.73) afirma que "o tratamento literário na narrativa moderna sofreu profunda influência do vitalismo existencial de Bérgson e do romance de Proust". Nunes (2002) completa esse pensamento, afirmando que o contraste entre a duração interior com a objetividade do 
tempo cronológico é um dos principais condutos da tematização do tempo no romance. Até então, havia o romance experimental do século XIX, com a aplicação do conceito científico do tempo à vida humana. Já o romance que o sucede beneficia-se do conceito bergsoniano da dureé, que se identifica com o "fluir da consciência e da sensibilidade, jamais idêntico a si mesmo, sempre diverso, cujo ritmo é o próprio ritmo da vida. O fluxo de consciência será, na criação romanesca, o eixo principal da transformação do enredo". (NUNES, 2002, p.57).

O precursor a aplicar numa obra literária essa dimensão atemporal foi Laurence Sterne com Tristram Shandy, publicado em diversos volumes, sendo os dois primeiros em 1760. Na obra, Sterne disserta a respeito do conceito de dureé, sendo o precursor do que Mendilow chama de "distância psicológica". Nesse romance, até hoje ousado em sua forma, Sterne oferece ao leitor a expectativa de ler a história da vida do narrador autodiegético; entretanto, digressões e mais digressões se sucedem, ao sabor da memória afetiva e do capricho, de modo que, ao findar o texto, o narrador consegue chegar no dia se seu nascimento. Sterne é mestre não apenas dos assuntos truncados que se iniciam num capítulo e se reatam muitos capítulos adiante, da quebra do romance de tempo linear, dos prefácios situados já no meio da narrativa, mas também de um tipo de digressão que, embora pareça romper o ritmo da ação, faz progredir a trama, pois ela constitui o próprio romance: suprimidas as digressões, não existiria Tristram Shandy.

Em outras palavras, Sterne usa o tempo numa dimensão que não é comum na ficção do século XVIII e menos ainda na do século XIX. A técnica de fragmentação, o processo de digressões já apontado, acrescentam-se os episódios que se cortam à revelia da sucessão de capítulos, criando a ambiência do romance e estruturando os caracteres. Passado e presente já não se separam estanques, mas o primeiro se atualiza no segundo, pelo processo de associação de ideias, verdadeira teia responsável pela estruturação da narrativa.

Esses recursos, que posteriormente serão retomados na análise da narrativa, se constituem como verdadeiras chaves de leitura para nosso corpus e, de certa maneira, para toda a ficção clariceana.

\section{Estudo analítico: A questão temporal em Perto do Coração Selvagem}

Iniciemos efetivamente a análise de Perto do Coração Selvagem, utilizando o que Nunes (2002, p.77) chama de inteligência narrativa do leitor, isto é, "retomando a história na direção inversa a da ordem narrada, abrindo os caminhos para uma leitura interpretativa (do texto como um todo), ou explicativa (que tenta deduzi-lo de um modelo analítico)", pois o nosso objeto é todo montado em flashes, como veremos no decorrer desta análise. Não é por acaso, que em 1967, Massaud Moisés afirmou:

[...] Clarice Lispector representa na atualidade
literária brasileira (e mesmo portuguesa a a
ficcionista do tempo por excelência: para ela, a
grande preocupação do romance (e do conto)
reside no criar o tempo, criá-lo aglutinando
aos personagens. Por isso correspondem
suas narrativas a reconstruções do mundo
não em termos de espaço, mas de tempo,
como se, apreendendo o fluxo temporal, elas
pudessem surpreender a face oculta e imutável
da humanidade e da paisagem circundante.
(MOISÉS, apud SÁ, 1979, p. 77).

Partindo de um viés de análise que considera a temporalidade em Perto do Coração Selvagem podemos perceber que o texto pode ser dividido em duas partes. Na primeira, dividida em nove capítulos, temos dois planos narrativos que se alternam: o da infância e o da vida adulta de Joana, a protagonista do romance. A história de Joana é montada por flashes, nos quais aparecem suas fantasias de criança ao lado do pai, a visita de um amigo do pai que traz algumas informações sobre a personalidade 
de sua mãe já falecida, o contato conflituoso com a tia burguesa que a adotara após a morte do pai e a puberdade de Joana, em circunstâncias problemáticas. Alternados com esses flashes, temos outros segmentos da vida adulta da personagem protagonista, já casada com Otávio: sua vivência cotidiana, o passeio com o marido, seus momentos de alegria e um diálogo com a "mulher da voz" que a impressionara, seguido de reflexões sobre a inconsciência dessa personagem. O último capítulo da primeira parte, intitulado "Otávio", dedicado ao marido, associa os dois planos narrativos e registra o sentido de seu amor.

A segunda parte do livro desenvolve-se em torno do triângulo amoroso. Joana, sem filhos, vive em sua casa enredada nos afazeres domésticos. Ela já não pode contar com o abrigo do professor, como o fizera em sua infância, pois o procurara antes do seu casamento e a imagem positiva que tinha dele se desfizera. Por outro lado, Otávio tinha uma amante: Lídia, sua ex-noiva, que estava grávida. Joana aprecia-o sem a máscara social, quando Otávio está dormindo; suas fantasias são projetadas igualmente em um amante, após conhecer o relacionamento extraconjugal do marido. Joana briga, logo depois, com o marido e o amante se afasta.

A narrativa se encerra com a personagem feliz com a "partida dos homens" (marido e amante): considera-se liberta e capaz de sentir o mundo em sua plenitude. No último capítulo, há um monólogo da protagonista. O narrador, identificado com a perspectiva de Joana, coloca-a em uma situação vital superior à que tivera na infância: sua autenticidade deixa-a forte e nada impedirá seu caminho até a morte-sem-medo: de qualquer luta ou descanso, se levantará forte e bela como um cavalo novo.

Considerando as palavras de Nunes (1995. p.19) para quem são três os aspectos fundamentais que devem ser abordados em Perto do coração selvagem: “o aprofundamento introspectivo, a alternância temporal dos episódios e o caráter inacabado da narrativa" podemos afirmar que é na experiência interior de Joana que a ação romanesca está centrada. $\mathrm{Na}$ primeira parte do romance, o que prevalece são as lembranças, sensações e sentimentos da protagonista. Mesmo heterodiegeticamente 4 , utilizando o monólogo interior em combinação com o estilo indireto livre, o mundo interno do personagem é trazido para o leitor como se fosse revelado pela própria protagonista. Todas as suas vivências praticamente anulam o mundo exterior, que além de insignificante, só aparece para colaborar com o conflito interior de Joana.

Com a "consciência em crise" (NUNES, 1995, p.20), a introspecção de Joana é identificada nos primeiros trechos do romance. É explícito o uso do tempo e da sondagem psicológica, característica do romance, (que posteriormente tornar-se-ia uma das marcas das narrativas de Lispector) como aponta o fragmento a seguir:

\begin{abstract}
Houve um momento grande, parado, sem nada dentro. Dilatou os olhos, esperou. Nada veio. Branco. Mas de repente, num estremecimento deram corda no dia e tudo recomeçou a funcionar, a máquina trotando, o cigarro do pai fumegando, o silêncio, as folhinhas, os frangos pelados, a claridade, as coisas revivendo cheias de pressa como uma chaleira a ferver. (LISPECTOR, 1980, p.11)
\end{abstract}

Isolada do mundo externo, Joana desde a infância, além de solitária, está em permanente oposição com os outros. Órfã, entra em atrito com a tia, após ser flagrada roubando um livro, situação da qual ela sai tranquilamente, dizendo apenas que roubará quando tiver vontade.

- Sim, roubei porque quis. Só roubarei
quando quiser. Não faz mal nenhum.
- Deus me ajude, quando faz mal Joana?
- Quando a gente rouba e tem medo.
Eu não estou contente nem triste.

(LISPECTOR, 1980, p.52)

4. O narrador heterodiegético é aquele que conta uma história da qual não participa diretamente, conforme designação do termo cunhado por Gérard Genette (1972). 
Após o episódio, os tios decidem interná-la em um colégio. Posteriormente, ela vê no marido "um estranho, que ela ama hostilizando, um inimigo potencial que ela odeia amando". (NUNES, 1995, p.20). A vida de mulher casada, com a rotina doméstica, não dá conta de tranquilizar sua inquietação interior. Percebe-se, como já apontamos, que os escassos acontecimentos exteriores, como o roubo do livro, por exemplo, servem apenas para solidificar o seu isolamento, a distância do mundo concreto e daqueles que a rodeiam. O monólogo interior é um dos recursos que a autora lança mão para verbalizar as sensações de Joana:

\begin{abstract}
A liberdade que às vezes sentia não vinha de reflexões nítidas, mas de um estado como feito de percepções por demais orgânicas para serem formuladas em pensamentos. Às vezes no fundo da sensação tremulava uma idéia que lhe dava leve consciência de sua espécie e de sua cor. O estado para onde deslizava quando murmurava: eternidade (LISPECTOR, 1980, p.44)
\end{abstract}

Tais sensações também são descritas pela técnica do fluxo de consciência. Essa técnica narrativa tem sua gênese no romance Les lauriers sont coupés, de Edouard Dujardin, publicado em 1887. Anos depois, Dujardin publica uma obra buscando explicar esse recurso que intitulou de monólogo interior. A confusão entre fluxo de consciência e monólogo interior é muito comum. Franco Júnior (2009, p.48) afirma que um dos fatores de distinção, reside no "fato de que o primeiro não cria o efeito de perda de controle da consciência da personagem - traço característico do segundo". No entanto, é importante salientar que tais recursos podem estar articulados no mesmo texto. Leite (1985) afirma que o fluxo de consciência é a expressão direta dos estados mentais que fluem de maneira desarticulada, sem uma sequência lógica, criando um desenrolar ininterrupto dos pensamentos das personagens ou do narrador.

Dessa maneira, pautando-nos no estudo do fluxo de consciência, podemos mencionar que a narrativa intercepta o presente e o passado, quebrando os limites espaço-temporais, quebrando a linearidade da narrativa e criando certa confusão entre pensamentos dos personagens ou narrador e a situação presentemente narrada. Vale assinalar que Humphrey (1976), um dos maiores teóricos a respeito do tema, afirma que a consciência é o fundo sob o qual se projeto o material romanesco ficcional. Desse modo, a técnica de fluxo de consciência fica explícita em uma das divagações de Joana, quando enfim, ela se separa do marido e do amante com quem por pouco tempo se envolvera.

De manhã. Onde estivera alguma vez, em
que terra estranha e milagrosa já pousara
para afora sentir-lhe o perfume? Folhas secas
sobre a terra úmida. O coração apertou-se-
lhe devagar, abriu-se, ela não respirou um
momento esperando... Era de manhã, sabia
que era de manhã... Recuando como pela mão
frágil de uma criança, ouviu, abafado como em
sonho, galinhas arranhando a terra. Uma terra
quente, seca... o relógio batendo tin-dlen...
tin...dlen... o sol chovendo em pequenas rosas
amarelas e vermelhas sobre as casas... Deus, o
que era aquilo senão ela mesma? Mas quando?
Não sempre... (LISPECTOR, 1980, p.202)

A temporalidade não linear, que cria uma espécie de vai-e-vem de acontecimentos fora da ordem cronológica e que acompanha a errância do interior da personagem, passando de um a outro dos pequenos círculos de sua vida dispersa, “é sobrepujada, já na segunda parte do romance, pela sucessão dos incidentes que formam o encadeamento de uma intriga de amor" (NUNES, 1980, p.23). Como foi dito, um triângulo amoroso se forma entre Joana, o esposo e uma ex-noiva dele. Joana, abandonada pelo marido e por um amante, parte para uma viagem ao mais profundo de si mesma, fundindo sua infância com sua morte. Tais imagens se fundem num monólogo interior no último capítulo do romance.

Deus por que não existe dentro de mim? Por que me fizestes separada de ti? Deus vinde a mim, eu não sou nada, eu sou menos que o pó e te espero todos os dias e todas as noites, ajudai-me, eu só tenho uma vida e essa vida escorre pelos meus dedos [...] Só então viverei maior do que na infância, serei brutal e malfeita como uma pedra, serei leve e vaga como o que 
se sente e não se entende [...] e nada impedirá meu caminho até a morte-sem-medo, de qualquer luta ou descanso me levantarei forte e bela como um cavalo novo. (LISPECTOR, 1980, p.212).

Retomando os conceitos de tempo na narrativa, utilizados por Benedito Nunes (2002) e também por Umberto Eco (1994), podemos perceber que, no nosso corpus, o tempo da história e o tempo do discurso se fundem e, se não fosse difícil quantificar, o tempo da leitura também se fundiria com ambos. Eco (1994, p.65) afirma que esse tipo de texto "cria um artifício para que o leitor entre no ritmo que o autor julga necessário para a fruição do texto". Dessa forma, as divagações, sensações e lembranças de Joana talvez levem o mesmo tempo para serem lidas e "sofridas" pela protagonista. Outro aspecto, então, passa a ser percebido no texto e pode ser assinalado e está associado à temporalidade no romance mencionado: o aspecto memorialístico, conforme veremos a seguir.

\section{Perspectiva memorialista em Perto do Coração Selvagem}

Segundo Rodrigues (2010, p.836) o memorialismo pode ser entendido como uma "narrativa ficcional interessada em apresentar a vida de uma pessoa, vida inventada, ainda que alguns casos suscitem graus de aproximação como alguém fora da ficção, geralmente o autor”. A ficção biográfica, assim, é uma narrativa de fatos inventados que privilegia, na sua conformação fabular e na sua configuração estrutural, a trajetória, parcial ou integral, da vida de alguém.

Não se pode confundir ficção memorialística com biografismo, pois aquela liberta o leitor da tensão referencial. Mesmo quando pensamos na escritora Clarice Lispector, especificamente em uma época de sua vida em que escreveu crônicas e contos para diversos jornais, afirmando por diversas vezes que aquela produção era irremediavelmente sua vida real, ou ainda, quando pensamos que Perto do Coração Selvagem narra a vida de Joana, órfã como Clarice (Lispector ficou órfã na infância e foi criada pelas irmãs, tendo depois uma vida problemática, assim como a protagonista do romance), podemos dizer apenas que, segundo as palavras de Rodrigues (2010, p.838) "a memória funciona como aproximação entre a matéria e o que não é matéria, ou seja, escrever significa filtrar uma experiência, e essa experiência por sua vez, converte-se em memória, em matéria de memória".

Levando-se em conta esta temporalidade ondulante que acompanha os questionamentos existenciais de Joana, passando de um momento para outro de sua vida, podemos destacar, nesse romance, que a "experiência memorialista é uma imaginação das experiências vividas" (RODRIGUES, 2010, p.837) e está ligada com a configuração cronológica do romance.

\section{Percebe-se que, em Perto do Coração Selvagem,} os fatos da vida de Joana não possuem uma sequência linear. $O$ primeiro capítulo, intitulado "O pai", inicia com Joana conversando com seu pai, ainda na infância. Já no segundo capítulo, intitulado "O dia de Joana", a protagonista, através de um monólogo interior, afirma como se sente livre, quando o esposo Otávio sai de casa para trabalhar, deixando- a sozinha. E neste vaie-vem, o romance é constituído, criando uma forte tensão estrutural-cronológica e quebrando a expectativa do leitor.

O efeito resultante da estratégia narrativa e da tática gramatical leva o leitor a perder a sequência de fatos. Esse efeito provocado pela estruturação dos motivos (termo cunhado por Tomachevsky), de funções (segundo Roland Barthes), não chega a produzir uma perda de sequência, mas incomoda o leitor, deixando-o sempre em alerta para situar- 
se na narrativa e entender que a vida de Joana só poderá ser entendida pelo viés da reminiscência, isto é, quando se fundem as várias fases de sua vida, isso através da quebra cronológica de um trecho da narrativa para outro, destacando as principais passagens de sua infância, adolescência e maturidade e construindo, dessa maneira, um painel de educação existencial, que discute a situação conflitiva de um Ser inserido em um determinado tempo e espaço.

\section{Considerações finais}

Ao término deste estudo, evidencia-se a importância dos estudos acerca da questão temporal que, como foi dito no início deste trabalho, constituem chaves de leitura de Perto do Coração Selvagem. Podemos perceber que as preocupações existencial e mística de Joana, a protagonista, serão apresentadas e representadas através da presentificação, da distorção de acontecimentos e das memórias que são apresentadas ao leitor por meio do tempo psicológico e das técnicas narrativas usadas pela escritora, ligadas à subjetividade do tempo.

Analisar um texto literário é uma ação, conforme mencionamos no início, que parte de um recorte singular. Isso implica em escolhas e exclusões possíveis. Pensar a temporalidade de um romance não significa, portanto, esgotar suas possibilidades de compreensão, seja porque a interpretação é uma ação que se dá em movimento e não termina, seja porque as possibilidades de interpretação inscritas no texto ficcional e nas épocas em que ele vai se inserindo não são únicas, nem irrefutáveis sequer excluem a legitimidade de outras lentes de observação do texto.

\section{Referências}

ECO, Umberto. Seis passeios pelos bosques da ficção. São Paulo: Companhia das Letras, 1994.
FRANCO JÚNIOR, Arnaldo. Operadores de leitura da narrativa in BONNICI, Thomas; ZOLIN, Lúcia Osana. (orgs). Teoria Literária: Abordagens históricas e tendências contemporâneas. Maringá: Eduem, 2009.

GENETTE, Gérard. Figures III. Paris: Seuil, 1972.

HUMPREY, Robert. O fluxo da consciência. São Paulo: McGraw-Hill do Brasil, 1976.

LEITE, Lígia Chiappini Moraes. O foco narrativo. São Paulo: Ática, 1985.

LISPECTOR, Clarice. Perto do coração selvagem. Rio de Janeiro: Nova Fronteira, 1980.

NUNES, Benedito. O tempo na narrativa. São Paulo: Ática, 1999.

NUNES, Benedito. O drama da linguagem: Uma leitura de Clarice Lispector. São Paulo: Ática, 1995.

NUNES, Benedito. O dorso do tigre. São Paulo: Perspectiva, 1969.

RODRIGUES, Milton Hermes. C. et al. Ficção memorialística e estruturação cronológica. II COLÓQUIO DA PÓS-GRADUAÇÃO EM LETRAS, 2010, Assis. Anais... Assis: UNESP/ Assis, 2010, p. 836-845, 2010.

\section{SÁ, Olga de. A escritura de Clarice Lispector.} São Paulo: Vozes, 1979.

SCHULER, Donaldo. Teoria do romance. São Paulo: Ática, 1989.

Recebido em: 16 de junho de 2017.

Aprovado em: 19 de outubro de 2017. 